\title{
Estimation of cardiovascular diseases (CVD) risk using WHO/ISH risk prediction charts in tribal population of Chamarajanagar district, Karnataka
}

\author{
Amoghashree (Senior Resident)**, D. Sunil Kumar (Associate Professor), \\ Praveen Kulkarni (Associate Professor), M.R. Narayana Murthy (Professor \& Head)
}

Department of Community Medicine, JSS Medical College, JSS Academy of Higher Education and Research, Mysore, India

\section{A R T I C L E I N F O}

\section{Keywords:}

CVD

Non-communicable diseases

Tribal population

WHO/ISH risk prediction

\begin{abstract}
A B S T R A C T
Background: India is the home to almost half the tribal population of the world and is second to Africa in terms of tribal mass. Because of acculturation many of these tribal have come out and relocated themselves outside the forest. As a result, life style has been changed which resulted in development of non-communicable diseases. In this context this study was carried out to estimate the prevalence CVD risk factors and to predict the cardiovascular events among tribal population, utilizing WHO/ISH risk prediction chart.

Methods: Community based cross sectional study done for a period of 3 months. Information regarding socio demographic profile and risk factors were collected. Anthropometric measurements, Blood pressure, Random capillary Blood glucose were recorded. WHO/ISH risk prediction chart for SEAR D was used to assess the CVD risk in next 10 year. Data was analysed used SPSS version 25. Results were expressed as percentage and mean. Chi square test was used to find out the association.

Results: Among 120 study population, 33.3\% belongs to the age group of 40-49 years, 55\% were females, 59.2\% belongs to nuclear family, $39.2 \%$ were unskilled and $62.5 \%$ were uneducated. Prevalence of CVD risk factors among were as follows: Tobacco consumption (25.8\%), alcohol (16.7\%), diabetes (3.33\%), hypertension (48.3\%) and obesity (19.2\%). 62.5\% population had less than $10 \%$ (mild) risk and $11.7 \%$ had $\geq 40 \%$ (high) risk of developing.

Conclusion: Aggressive screening is needed as many were unaware about theirs NCD status.
\end{abstract}

\section{Introduction}

The Indian Constitution under Article 342 Clause 9 (i), declared around 255 tribes who belongs to 17 states as 'Scheduled Tribes'. They are listed in Article 366 (25) on the criteria of geographical isolation, backwardness, primitive agriculture, poverty, low literacy and poor health. The constitution protects their distinctive life from social injustice, exploitation and discrimination to develop them to be on par with others for inclusive national growth. ${ }^{1}$ India is second to Africa in terms of tribal mass. As per 2011 census India accounts to $8.2 \%$ of Indian population. ${ }^{2}$ The total number of tribal people recognized by the Government in Karnataka is about $42,48,978$ which is $6.95 \%$ of the total population of the State. ${ }^{3}$ They thus constitute a substantial portion of our population. Yet, they are ignored by our policy maker. ${ }^{4}$ Because of acculturation and also in the name of wild life conservation many of these tribes are forced to relocated themselves outside the forest. As a result of this, life style has been changed which resulted in development of non-communicable diseases (NCDs) like hypertension, diabetes, cardiovascular diseases (CVDs) etc. Though many studies related to non-communicable diseases have been conducted in urban and rural areas, data related to tribal communities is limited. As CVDs constitute the leading cause among NCDs in India, the present study was conducted with the objectives, to estimate the prevalence of CVD risk factors and to predict the development of CVD events using WHO/ISH risk prediction chart among tribal population of Chamarajanagar district, Karnataka, India.

\section{Materials and methods}

Community based cross sectional study was conducted for a period of 3 months among tribal population of 5 tribal hamlets of B R Hills of Chamarajanagar District of Karnataka, India. Participants were selected based on convenience sampling. Inclusion criteria: Individuals who were 40 years of age and those who were willing to participate in the study by giving informed consent were included. Exclusion criteria: Individuals who did not wish to participate in the study and Individuals

\footnotetext{
* Corresponding author.

E-mail address: amoghashree@jssuni.edu.in (Amoghashree).
} 
Table 1

Socio-demographic characteristics of the study participants $(\mathrm{n}=120)$.

\begin{tabular}{lll}
\hline Variables & & Frequency (\%) \\
\hline \multirow{2}{*}{ Age } & $\leq 50$ years & $58(48.3)$ \\
Sex & $>50$ years & $62(51.7)$ \\
Education & Fale & $54(45)$ \\
& Female & $66(55)$ \\
Occupation & Illiterate & $75(62.5)$ \\
& Literate & $45(37.5)$ \\
Type of Family & Employed & $63(52.5)$ \\
& Unemployed & $57(47.5)$ \\
Family size & Nuclear & $71(59.2)$ \\
Socio-economic status (Modified B & Joint family & $3(2.5)$ \\
G Prasad) & Three generation family & $46(38.3)$ \\
& $1-4$ & $63(52.5)$ \\
& $\geq 5$ & $57(47.5)$ \\
& Upper middle class and & $10(8.4)$ \\
& above & $15(12.5)$ \\
& Middle class & $31(25.8)$ \\
& Lower middle class & $64(53.3)$
\end{tabular}

with confirmed coronary heart disease, stroke or other atherosclerotic diseases was excluded. Socio demographic profile and information regarding smoking, alcohol, diabetes and hypertension status were collected using pretested and structured questionnaire by interview. Anthropometric measurements like height, weight, waist circumference and hip circumference were recorded. Blood pressure was recorded using digital Omron apparatus and Accucheck glucometer was used to record Random capillary Blood glucose. WHO/ISH risk prediction chart for SEAR D (South East Asian sub-Region D) was used to predict the risk of developing CVD events in next 10 years. Statistical analysis: Data was entered in Microsoft excel sheet and analysed using SPSS software version 25. Descriptive statistics like percentage and mean, SD were used to describe the variables. Chi square test was used to find out the association.
Table 2

Distribution of Risk factors of CVD among study participants (N = 120),

\begin{tabular}{llll}
\hline Risk factors & & Frequency & Percent \\
\hline Age & $\leq 50$ years & 58 & 48.3 \\
& $>50$ years & 62 & 51.7 \\
Sex & Male & 54 & 45 \\
& Female & 66 & 55 \\
Smoking & & 44 & 36.7 \\
Alcohol & & 20 & 16.7 \\
Diabetes & & 4 & 3.3 \\
Hypertension & & 58 & 48.3 \\
Diet & Veg & 12 & 10 \\
& Mixed & 108 & 90 \\
BMI & Underweight & 40 & 33.3 \\
& Normal & 41 & 34.2 \\
& Overweight & 16 & 13.3 \\
Family history of CVDs & Obese & 23 & 19.2 \\
& Present & 4 & 3.33 \\
\hline
\end{tabular}

\section{Results}

Among 120 study population, mean age was $55.3 \pm 10.9$ years and majority, $51.7 \%$ were in age group of more than 50 years, $55 \%$ were females, majority were illiterate $(62.5 \%), 52.5 \%$ were engaged in one or the other work whereas $47.5 \%$ were unemployed, $59.2 \%$ belongs to nuclear family, $52.5 \%$ had family members $<4$ and $53.3 \%$ belongs to lower socio-economic class according to modified B G Prasad classification (Table 1).

Prevalence of diabetes was $3.3 \%$. Only $2.5 \%$ of the study population knew their diabetic status. (Graph 1).

Prevalence of hypertension was noted to be $48.3 \%$. and out of these $32.8 \%$ of the study participants knew their hypertensive status. (Graph 2).

Prevalence of CVD risk factors among study population were as follows: smoking - 36.7\%, alcohol - 16.7\%, diabetes - 3.33\%, hypertension $-48.3 \%$, obesity $-19.2 \%$ and family history of CVDs $-3.33 \%$
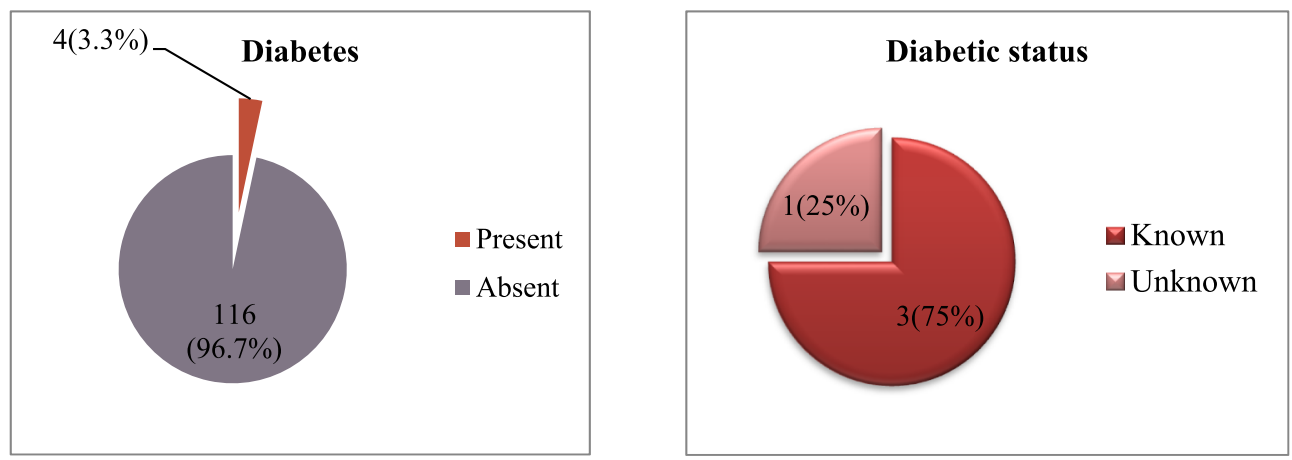

Graph 1. Prevalence of diabetes $(\mathrm{N}=120)$.
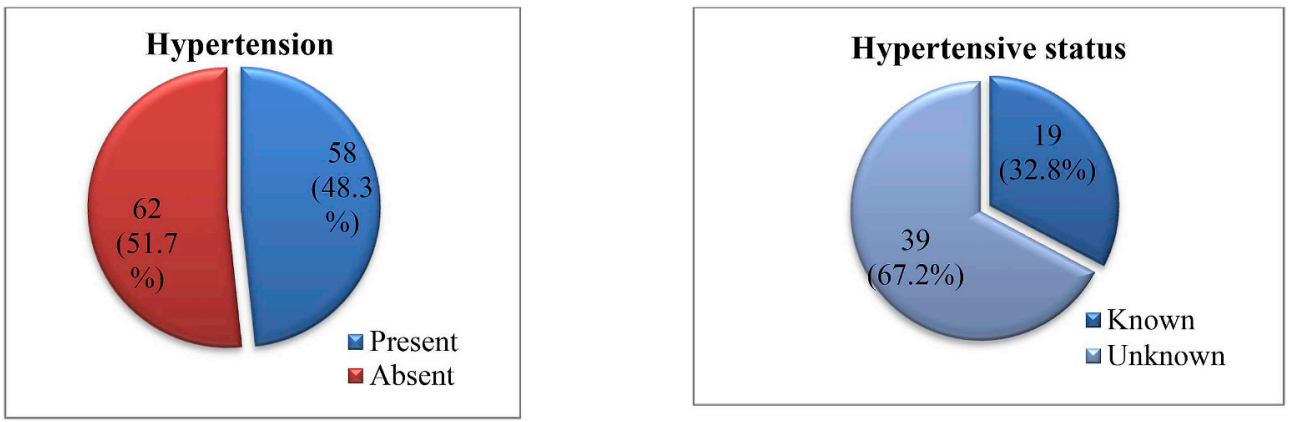

Graph 2. Prevalence of hypertension $(\mathrm{N}=120)$. 


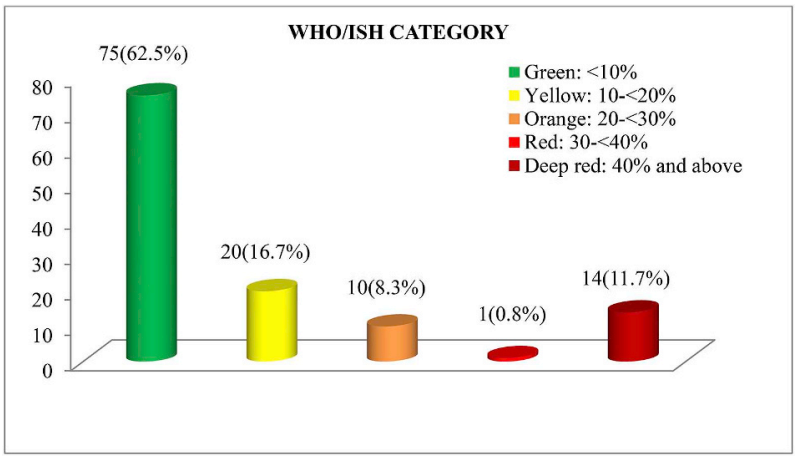

Graph 3. Prediction of ten-year total CVD risk using WHO/ISH sear $\mathrm{d}$ charts $(\mathrm{N}=120)$.

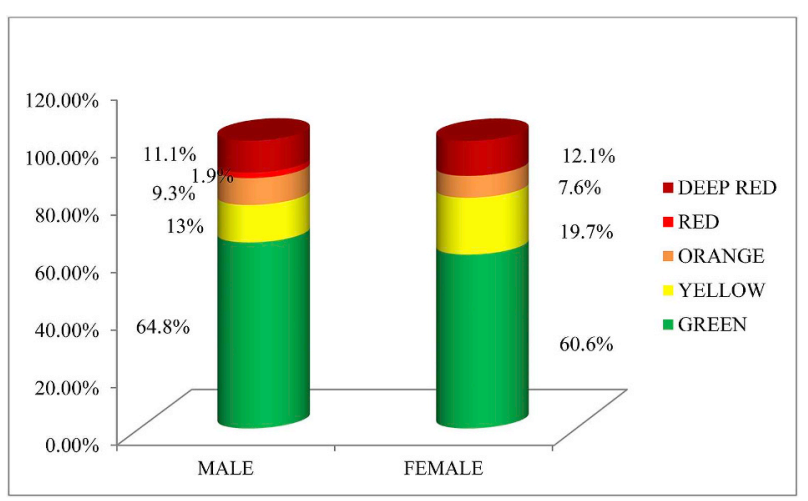

Graph 4. Gender wise distribution of predicted 10 year CVD risk $(\mathrm{N}=120)$.

(Table 2).

$62.5 \%$ of study population had less than $10 \%$ (mild) risk and $11.7 \%$ had $\geq 40 \%$ (high) risk of developing CVD in 10 years. (Graph 3).

Male and female have almost equal risk of developing CVDs in next 10 years. (Graph 4).

Association was seen between age, occupation, education, BMI, hypertension and smoking with CVD risk at $\mathrm{P}$ value $<0.05$ (Table 3 ).

\section{Discussion}

Among the study population, mean age was found to be $55.3 \pm 10.9$ years. In the present study $62.5 \%$ were illiterates, which is in contrast with the study conducted by Siddalingappa $\mathrm{H}$ et al. Kandpal et al. studies which shows $43 \%$ and $28.8 \%$ respectively. ${ }^{2,5}$ Where as it is
$53.5 \%$ according to Gupta VK et al. $^{6}$ which is nearly similar to our study.

$47.5 \%$ are unemployed which is in contrast with Gupta VK et al. ${ }^{6}$ where unemployment is seen in $13.6 \%$.

$59.2 \%$ lives in nuclear family, the similar trend was seen in Siddalingappa $\mathrm{H}$ et al. ${ }^{2}$ (60.8\%).

In this study, $52.5 \%$ had family members less than 4 and $53.3 \%$ belongs to lower socio-economic class according to modified B G Prasad classification.

Hypertension is prevalent in $48.3 \%$ which is similar with Kandpal et al. study where hypertension was noted among $43.4 \%$, but this is in contrast with Gupta VK et al. where hypertension was seen in $27.1 \%$ and in Mandani B et al. it was $16.9 \%$. $^{5,6,7}$

Prevalence of diabetes was $3.3 \%$ and among study population only $2.5 \%$ of them knew their diabetic status. According to Radhakrishnan $\mathrm{S}$ et al. prevalence of Diabetes among tribal population was 5.3\%. ${ }^{4}$ High prevalence is noted in Ramalingam $S$ et al. (38.2\%). ${ }^{8}$

Prevalence of hypertension was $48.3 \%$ and out of these $32.8 \%$ of the study population knew their hypertensive status. Similar result is seen in Kandpal et al. where prevalence is $43.4 \%,{ }^{5}$ but this result is in contrast with Gupta VK et al., Mandani B et al. and Ramalingam S et al. study, where hypertension was seen in $27.1 \%, 16.9 \%$ and $14.5 \%$ respectively. ${ }^{6,7,8}$

Smoking was seen in $36.7 \%$ study population i.e. $25.8 \%$ are smokers and $10.8 \%$ had habit of tobacco chewing whereas Siddalingappa $\mathrm{H}$ et $\mathrm{al}^{2}$ reported smoking among $25.6 \%$ and tobacco chewing among $24.8 \%$. In Gupta VK et al. ${ }^{6}$ study, $11.8 \%$ smokes and $39.7 \%$ consumes smokeless tobacco. Similar prevalence of smoking is seen in Mandani B et al. (38.5\%). ${ }^{7}$ Decreased prevalence was noted in Kandpal et al. and Ramalingam $S$ et al. as 13.9 and $12.7 \%$ respectively and high prevalence was noted in Misra PJ as $84 \% .{ }^{5,8,9}$

In this study alcohol consumption was seen among $16.7 \%$ whereas Mandani B et al. and Ramalingam S et al. showed alcohol consumption among $5.5 \%$ and $7.3 \%$ subjects respectively. ${ }^{7,8}$ Study conducted by Gupta VK et al., Kandpal et al., Misra PJ showed high alcohol consumption among subjects as $26.6 \%, 37.5 \%$ and $67 \%$ respectively. ${ }^{5,6,9}$

In this study $90 \%$ consumes mixed diet where in Gupta VK et al. $81.5 \%$ consumes mixed diet. ${ }^{6}$ Obesity was seen among $19.2 \%$ where in Gupta VK et al. it was $13.2 \%$ and in Misra PJ overweight was seen in $16 \% .^{6,9}$

In the present study family history of CVDs is seen in $33.3 \%$ of the study population.

$62.5 \%$ of study population had less than $10 \%$ (mild) risk, $16.7 \%$ had $10-<20 \%$ risk, $8.3 \%$ had $20-<30 \%$ risk, $0.8 \%$ had $<40 \%$ risk and $11.7 \%$ had $\geq 40 \%$ (high) risk of developing CVD in 10 years. Male and female have equal risk of developing CVDs in next 10 years.

Table 3

Association between CVD risk factors and CVD risk category.

\begin{tabular}{|c|c|c|c|c|c|c|}
\hline \multirow[t]{2}{*}{ Risk factors } & & \multicolumn{3}{|c|}{ WHO/ISH category ${ }^{\mathrm{a}}$} & \multirow[t]{2}{*}{ Total } & \multirow[t]{2}{*}{$P$ value } \\
\hline & & Mild & Moderate & Severe & & \\
\hline \multirow[t]{2}{*}{ Age in years } & $<50$ & $52(89.7 \%)$ & $4(6.9 \%)$ & $2(3.4 \%)$ & $58(100 \%)$ & 0.001 \\
\hline & $>50$ & $23(37.1 \%)$ & $26(41.9 \%)$ & $13(21.0 \%)$ & $62(100 \%)$ & \\
\hline \multirow[t]{2}{*}{ Occupation } & Employed & $47(74.6 \%)$ & $11(17.5 \%)$ & $5(7.9 \%)$ & $63(100 \%)$ & 0.015 \\
\hline & Unemployed & $28(49.1 \%)$ & $19(33.3 \%)$ & $10(17.5 \%)$ & $57(100 \%)$ & \\
\hline \multirow[t]{2}{*}{ Education } & Uneducated & $38(50.7 \%)$ & $24(32.0 \%)$ & $13(17.3 \%)$ & $75(100 \%)$ & 0.002 \\
\hline & Educated & $37(82.2 \%)$ & $6(13.3 \%)$ & $2(4.4 \%)$ & $45(100 \%)$ & \\
\hline \multirow[t]{3}{*}{ BMI } & Underweight & $20(50.0 \%)$ & $19(47.5 \%)$ & $1(2.5 \%)$ & $40(100 \%)$ & 0.001 \\
\hline & Normal & $29(70.7 \%)$ & $7(17.1 \%)$ & $5(12.2 \%)$ & $41(100 \%)$ & \\
\hline & Obesity & $26(66.7 \%)$ & $4(10.3 \%)$ & $9(23.1 \%)$ & $39(100 \%)$ & \\
\hline \multirow[t]{2}{*}{ Hypertension } & Present & $10(52.6 \%)$ & $3(15.8 \%)$ & $6(31.6 \%)$ & $19(100 \%)$ & 0.021 \\
\hline & Absent & $65(64.4 \%)$ & $27(26.7 \%)$ & $9(8.9 \%)$ & $101(100 \%)$ & \\
\hline \multirow[t]{2}{*}{ Smoking } & Present & $20(45.5 \%)$ & $14(31.8 \%)$ & $10(22.7 \%)$ & $44(100 \%)$ & 0.006 \\
\hline & Absent & $55(72.4 \%)$ & $16(21.1 \%)$ & $5(6.6 \%)$ & $76(100 \%)$ & \\
\hline
\end{tabular}

${ }^{\text {a }}$ Mild-Green ( $\left.<10 \%\right)$, Moderate- Orange $(10 \%-<20 \%)$ \&Yellow $(20 \%-<30 \%)$ and Severe- Red $(30 \%-<40 \%) \&$ Deep red $(\geq 40 \%)$. 
Association was seen between age, occupation, education, BMI, hypertension and smoking with CVD risk at $\mathrm{P}$ value $<0.05$. As the age increases, risk of CVD is also increases, risk is seen in unemployment's, severe risk is seen in illiterates when compared to educated. Severe risk is seen in obese when compared to normal and underweight stating that BMI is directly associated with CVD risk. Other risk factors like hypertension and smoking is also directly associated with CVD risk.

\section{Conclusion}

There is a need for screening for NCD among tribal population as many were unaware about theirs NCD status and also WHO/ISH risk prediction charts can be used as a simple tool at community level to estimate risk of CVD in next 10 years which helps them to take a preventive steps to lead a healthy life.

\section{Limitations}

Other CVD risk factors like Cholesterol, Physical activity and stress are not included.

\section{References}

1. Devadasan P. A Study About Life Style Of Jenu Kuruba Tribes Working As Unorganised Labourers. 2016; 2016.

2. Siddalingappa H, Hoogar V, Kumar SD, Pradeep TS, Renuka M. Sociodemographic and healthcare profile of tribal people in Bandipur Tiger Reserve area, Mysore, Karnataka, India. Int J Commun Med Publ Health. 2016;3:2655-2660.

3. Roy S, Hegde HV, Bhattacharya D, Upadhya V, Kholkute SD. Tribes in Karnataka: status of health research. Indian J Med Res. 2015;141(5):673-687. https://doi.org/10.4103/0971 5916.159586.

4. Radhakrishnan S, Ekambaram M. Prevalence of diabetes and hypertension among a tribal population in Tamil Nadu. Arch Med Health Sci. 2015;3:66-71.

5. Kandpal V, Sachdeva MP, Saraswathy KN. An assessment study of CVD related risk factors in a tribal population of India. BMC Publ Health. 2016;16(1):1.

6. Gupta VK, Rai N, Toppo NA, Kasar PK, Nema P. An epidemiological study of prevalence of hypertension and its risk factors among non migratory tribal population of Mawai block of Mandla district of central India. Int J Commun Med Publ Health. 2018;5:957-962.

7. Mandani B, Vaghani B, Gorasiya M, Patel P. Epidemiological factors associated with hypertension among tribal population in Gujarat. Nat J Commun Med. 2011;2:133-135.

8. Ramalingam Sudha, Murali A, Seethalakshmi A, Deepa R, Meera R, Rajendiran G. Cardiovascular disease risk factors in a tribal population of nilgiris. Natl J Res Community Med. 2012;1(2).

9. Misra PJ, Mini GK, Thankappan KR. Risk factor profile for non-communicable diseases among Mishing tribes in Assam, India: results from a WHO STEPs survey. Indian J Med Res. 2014;140:370-378 